\title{
Espaços ordinários e afetos na cidade: heterotopia fílmica em Avenida Brasília Formosa
}

Ordinary spaces and affections in the City: filmic heterotopia at A Venida Brasíla Formosa

\section{Fernanda Ribeiro Salvo}

Professora adjunta do curso de Jornalismo da Universidade Federal do Mato Grosso do Sul (UFMS). Doutora em Comunicação Social pela Universidade Federal de Minas Gerais (UFMG). fernandasalvo@hotmail.com

Recebido em 24 de novembro de 2015. Aprovado em 26 de março de 2016.

\section{Resumo}

Neste artigo analisaremos o filme Avenida Brasília

Formosa discutindo como a mise-en-scène articula elementos ao reinscrever a cidade do Recife. Para tanto, nos deteremos nas formas, enfatizando a criação das espacialidades e temporalidades. $\mathrm{O}$ filme focaliza a favela Brasília Teimosa, um dos marcos da reurbanização no Brasil nos últimos anos, criando na cena um espaço fortemente vinculado às experiências e afetos dos sujeitos filmados. Essa espacialidade, que ganha espessura na corporeidade do cotidiano, vem compor um "espaço outro", ou heterotopia, conforme conceitua Michel Foucault.

Palavras-chave: Vida Ordinária. Cotidiano. Heterotopia.

\section{Abstract}

In this article, we analyze the movie Avenida Brasilia Formosa, discussing how the mise-enscène articulates elements when reinstating the city of Recife, Brazil. Therefore, we will focus in the shapes, emphasizing the creation of spatialities and temporalities. The movie focus on the Brasília Teimosa favela, one of the redevelopment marks in Brazil in recent years, creating onthe scene a space tightly bound to the experiences and affections of the filmed subjects. This spatiality, gaining depth in everyday corporeity, composes an "other space", or heterotopia, as Michel Foucault conceptualizes.

Keywords: Ordinary life. Everyday life. Heterotopia. 


\section{Introdução}

O cinema brasileiro apresentou, nos últimos anos, significativa produção de filmes que se dedicaram a mostrar a vida comum e o cotidiano dos sujeitos ordinários. Para além das diferenças de abordagem e procedimentos narrativos, esse cinema recente tem buscado a aproximação com o Outro, investigando suas formas de aderência ao mundo e revelando evidente interesse pelas experiências e formas vividas ${ }^{1}$. Nesse artigo, discutiremos um dos filmes que se filia a essa vertente do cinema nacional: Avenida Brasília Formosa (, que nasceu de um projeto para o DOCTV (programa de financiamento da TV Brasil para documentários a serem exibidos na televisão) e teve uma versão com finalização de som e imagem para exibição em salas de cinema.

O filme de Mascaro focaliza o espaço urbano, já que a Brasília Formosa que nomeia o filme é uma avenida aberta na favela Brasília Teimosa, um dos marcos da reurbanização de Recife nos últimos anos. Ao tomar o cotidiano de seus moradores como ponto de vista, investigando os pertencimentos, laços de sociabilidade e formas vividas, a narrativa se distancia das falas midiáticas, que não raro apresentam as áreas periféricas e a favela sob o signo do exótico, da violência ou como a maior responsável pelos problemas da cidade.

Para compreender como a mise-en-scène $e^{2}$ aciona os elementos da escritura, reinscrevendo a própria cidade, nos deteremos sobre as formas, com ênfase nas espacialidades e temporalidades. Nosso pressuposto é o de que o filme, ao propor uma cena onde os tempos-espaços são constituídos em relação de estreita vizinhança com aqueles do cotidiano dos sujeitos filmados, propõe um gesto crítico sobre a realidade social. Buscando refletir sobre a constituição desse espaço de alteridade em Avenida Brasília Formosa, acionaremos a contribuição oferecida por Foucault (2006) que, ao escrever sobre os espaços no mundo moderno, conceitua as heterotopias como sendo espaços heterogêneos marcados por movimentos e entrecruzamentos, isto é, atravessados por um conjunto de relações que permitem defini-los. Ao investigar os espaços, Foucault ressalta a existência daqueles "que têm a curiosa propriedade de estar em relação com todos os outros posicionamentos,

1 Algumas produções realizadas nos últimos anos, nas quais a presença do cotidiano se faz marcante são $O$ céu de Suely (Karim Aïnouz, 2006); Casa de Alice (Chico Teixeira, 2007); Viajo porque preciso, volto porque te amo (Marcelo Gomes e Karim Aïnouz, 2009); As vilas volantes: o verbo contra o vento (Alexandre Veras, 2006); Acidente (Cao Guimarães, 2006); Morro do Céu (Gustavo Spolidoro, 2008); A falta que me faz (Marília Rocha, 2009); Uma Encruzilhada Aprazivel (Ruy Vasconcelos, 2007); Notas Flanantes (Clarice Campolina, 2009); O fim e o princípio (Eduardo Coutinho, 2005); Transeunte (Eryk Rocha, 2010); O Céu sobre os Ombros (Sérgio Borges, 2010), entre outros.

2 Jacques Aumont e Michel Marie, no Dicionário Teórico e Crítico de Cinema (2003), designam o termo Miseen-scène precisamente como "direção". Adotando tal prescrição, utilizaremos neste artigo o termo mise-en-scène para nos referirmos à direção e às escolhas estéticas contidas na cena fílmica. 
mas de tal modo que eles suspendem, neutralizam ou invertem o conjunto de relações que se encontram por eles designadas, refletidas ou pensadas" (Ibid., p. 414). Ou seja, espaços que se ligam uns aos outros produzindo sobreposições, contradições e oposições, mas cumprindo uma função em relação ao espaço restante.

Penso que o filme de Gabriel Mascaro vem compor algo à maneira de uma heterotopia microscópica ao propor, por meio da escritura do cinema, um espaço que ganha espessura e se adensa na corporeidade do cotidiano, no qual se efetiva a vida social, as ações e as práticas; no qual estão abrigadas as potências do viver.

\section{A encenação e a escritura da cidade}

Em Avenida Brasilia Formosa (2010), o diretor pernambucano Gabriel Mascaro retoma a crítica acirrada à verticalização da orla do Recife, discussão que manifestara anteriormente, noutra chave, em seu filme Um lugar ao sol (2009). As duas produções apresentam diferenças formais e de abordagem importantes, mas têm em comum a denúncia às políticas de urbanização, à especulação imobiliária desenfreada no Recife e à falta de planejamento da cidade. A comunidade que surge em Avenida Brasília Formosa é aquela oriunda da Brasília Teimosa, localidade que se tornou um dos marcos da reurbanização no Brasil em 2001, quando a população moradora da grande favela de palafitas à beiramar foi deslocada para a avenida que dá título ao filme. O processo se concretizou com a remoção dos moradores das áreas de risco de Brasília Teimosa, Vila Vintém e Poeirão para o Residencial Cordeiro. Na paisagem da orla surgiram enormes torres residenciais, nas quais foram instalados os apartamentos mais valorizados da cidade.

$\mathrm{Na}$ encenação, encontramos quatro não atores, moradores da favela, interpretando situações que fazem parte de seu cotidiano. São eles: Pirambu, o pescador; Fábio, que é garçom e videomaker amador; Débora, a cabeleireira e manicure que pretende chegar ao Big Brother Brasil; e Cauan, uma criança em idade escolar. Diante da câmera, eles realizam ações rotineiras em suas casas, locais de trabalho e lazer. Essa operação esfumaça as fronteiras entre a vida dos personagens e a mise-en-scène fílmica, tornando indistinguíveis as duas posições. A cena se constitui, pois, num espaço intervalar, abrigando os deslizamentos entre o real e a ficção, entre pessoa e personagem. Em razão disso, a narrativa coloca dificuldades para que enquadremos os sujeitos em identidades pré-figuradas, pois ficcionalizar é sempre uma forma de inventar a vida. No filme, não se trata apenas de pessoas interpretando seu cotidiano diante da câmera, mas de pessoas que buscam recursos para compor papéis num ambiente que lhes é absolutamente familiar, o que potencializa o trabalho de invenção de si. 
Se o ímpeto de Avenida Brasília Formosa é discutir a questão urbana, o diretor escolhe, para isso, um ponto de vista bem definido: parte da experiência dos próprios moradores do bairro, mostrando seu mundo e os modos de aderência a ele. No mesmo gesto, o filme revela os impactos da reurbanização sobre as vidas e o habitus - costumes, modos de fala, mediações culturais próprias à comunidade, espaços de pertencimento, ritmos e entonações regionais.

É justamente ao deixar a cena se contaminar por esses elementos do mundo dos sujeitos filmados que o filme inscreve um "lugar geográfico", que se condensa no vínculo entre os espaços e os afetos. Os próprios moradores parecem capazes de sugerir suas relações, suas interações efetivadas, num cotidiano pontuado por uma crispação que descarta a monotonia e a regularidade para se abrir à multiplicidade e às variações próprias à vida comum. Na cena, a cidade recebe a escala de um bairro em que estão expressos os modos de vida, as práticas compartilhadas, as vivências coletivas. Por isso mesmo, em Avenida Brasília Formosa, o bairro ganha dimensão sensível, inscrevendo-se como um "lugar", conforme o definiu Milton Santos, isto é, como "um espaço de exercício da existência plena", "um espaço vivido" de "experiência sempre renovada" (SANTOS, 2008, p. 114). Essa existência plena, diz Santos, é a força que atua como contraordem aos processos hegemônicos e aos "vetores da globalização" que se instalam no "lugar" para impor sua nova ordem, criando aceleradamente pobres, excluídos e marginalizados que cada vez mais se avolumam nas cidades, sem, entretanto, submeter-se permanentemente ao pragmatismo e à racionalidade dominante. O lugar é determinante, afirma Santos: é "naquele espaço", "de dentro do lugar", que cada pessoa ou grupo realiza o mundo à sua maneira.

Ao optar por uma mise-en-scène que nos faz experimentar o "lugar" como coisa sensível (a Avenida Brasília Formosa), Mascaro torna visível um espaço de alteridade quase sempre encoberto pelos poderes. Ao fazê-lo, o diretor desvela as potências, informalidades, improvisações e invenções daqueles que ali habitam, iluminando as zonas opacas onde se engendram as "astúcias dos fracos para tirar partido dos fortes", como escreveu Certeau (2011, p. 44). O trabalho realizado pelo filme evidencia que uma compreensão do espaço de Avenida Brasília Formosa passa também pela compreensão da vida de seus habitantes. É que as imagens nos colocam em contato, sistematicamente, com os hábitos, os gestos comuns, as falas corriqueiras e algumas maneiras de resistência e táticas por meio das quais os sujeitos ordinários investem imaginariamente sua cidade e inventam seu cotidiano. A narrativa se faz repleta de situações em que as práticas dos personagens são reveladoras da singularidade de seus modos de vida, de seu "virar-se" cotidianamente. Há algumas cenas que mostram, por exemplo, como os cômodos exíguos do interior das casas podem abrigar ao mesmo tempo cozinha e sala de estar, porque há 
divisões improvisadas feitas por seus habitantes. Em outra imagem vemos como a laje de um puxadinho se torna ambiente de lazer com a instalação de uma piscina de plástico para os adultos. Além disso, as caminhadas - essa forma de apropriação do espaço (Ibid., 2011) - são constantes em Avenida Brasília Formosa. Justamente os reiterados trajetos feitos a pé pelos personagens delineiam mais e mais o espaço, nos fazendo experimentar a cotidianidade do bairro e sua arquitetura, avenidas e vielas. Entre suas idas e vindas, os sujeitos da cena param na venda para comprar pão, batem na casa do vizinho, trocam cumprimentos e diálogos com aqueles que cruzam pelo caminho. Quando não estão em trânsito para o trabalho, eles vão à praia e aos forrós. O mundo de Brasília Formosa é composto de situações elementares da vida de todo dia: há a casa e a rua, o descanso e o trabalho, a rotina de pessoas comuns que existem e persistem na periferia de uma grande cidade. Se as imagens carregam inicialmente os elementos da experiência dos sujeitos filmados, é porque a encenação acontece, de fato, no espaço em que os personagens-atores habitam. Aquilo que faz parte do mundo vivido, compartilhado, e da história social, contamina fortemente a mise-en-scène fílmica, criada a partir desses indícios do mundo, do espaço efetivamente vivido, conforme alude Milton Santos.

O diálogo que essa temática estabelece com a Geografia Humana não é pequeno. Lefebvre (2001) refere-se ao conceito "heterotopia", de Michel Foucault, para pensar os espaços. De acordo com Lefebvre, os espaços da cidade podem ser classificados a partir de diversos critérios, dentre eles os relativos à isotopia-heterotopia. A isotopia se configura como o "espaço político, religioso, cultural, comercial etc" (LEFEBVRE, 2001, p. 61), ou seja, o espaço institucional, ligado à ordem e aos poderes. Em relação a essas isotopias, se desdobram as chamadas heterotopias. As categorias isotopia-heterotopia entram sistematicamente em relação e, seguramente, não convivem sem conflitos. A cidade inteira pode ser considerada uma isotopia ampla que engloba as outras, isto é, os subconjuntos espaciais que ao mesmo tempo lhe são subordinados e constituintes. É no espaço heterotópico que o fazer cotidiano se atualiza, com "seus ritmos, suas ocupações, sua organização espaço-temporal, sua cultura clandestina, sua vida subterrânea" (LEFEBVRE, 2001, p. 61).

Segundo Soja, Foucault já havia definido as heterotopias como "espaços característicos do mundo moderno, substituindo o hierárquico conjunto de lugares da Idade Média e o envolvente espaço de localização inaugurado por Galileu e infinitamente desdobrado no espaço de extensão e medida do moderno primitivo" (SOJA, 1993, p. 25, grifos do autor). Ao propor essa "virada espacial", Foucault destacou outra espacialidade da vida social: aquela efetivamente vivida e socialmente produzida, estreitamente ligada ao contexto das práticas sociais. Por isso mesmo, o espaço heterotópico se coloca como heterogêneo em relações e localizações: 
O espaço em que vivemos, que nos retira de nós mesmos, no qual ocorre o desgaste de nossa vida, nossa época e nossa história, o espaço que nos dilacera e corrói, é também, em si mesmo, um espaço heterogêneo. Em outras palavras, não vivemos numa espécie de vazio dentro do qual possamos situar indivíduos e coisas. Não vivemos num vazio passível de ser colorido por matizes variados de luz, mas num conjunto de relações que delineia localizações irredutíveis umas às outras e absolutamente não superponíveis entre si. (FOUCAULT apud SOJA, 1993, p. 25).

As heterotopias existem em todas as sociedades, assumindo contornos diferenciados em contextos particulares, modificando-se ao longo do tempo, "à medida em que a história se desdobra em sua espacialidade inerente" (loc. cit.). São exemplos de heterotopia citados por Foucault o cemitério, o museu, a feira, a cidade de férias, o bordel, a colônia, entre outros. As heterotopias são, pois, esses "espaços outros", raramente vistos devido "à visão bifocal que, tradicionalmente, encara o espaço como um construto mental ou como uma forma física" (Ibid., p. 26). Contudo, elas se inscrevem como instâncias reais que cumprem uma função em relação ao espaço restante por meio de relações, contradições e oposições. A espacialidade "efetivamente vivida" e "socialmente criada" de que fala Foucault encontra ressonância no viver cotidiano, sobretudo quando ele é posto em evidência a partir de um "lugar" e dos modos de vida compartilhados.

O filme de Gabriel Mascaro vem compor algo à maneira de uma heterotopia ao construir na cena uma espacialidade que somente ganha materialidade sensível vinculada aos tempos locais, às relações socialmente produzidas e à heterogeneidade próprias à vida comum. Em Avenida Brasília Formosa, presenciamos uma espacialidade resistente ao espaço formal e visível, pois o diretor decidiu mostrar a vida em comum, os laços de sociabilidade, a maneira como os sujeitos lidam com os dilemas de morar numa grande cidade, atravessada por ordens distintas de interesses econômicos e sociais. Estamos falando de um espaço social criado pelo filme que, a despeito do planejamento urbano e da ordem, se atualiza nos modos de vivenciar e transitar pelos lugares, nos maneirismos abrigados no bairro e na casa. Estão em jogo nesse espaço as práticas ordinárias, os contrapoderes, as potências de vida e os afetos que animam os sujeitos comuns. Como nos lembra Certeau (2011, p. 160), a cidade do discurso utópico e urbanístico é exatamente aquela que prima pela "criação de um sujeito universal e anônimo, que é a própria cidade". Contudo, lembremos que a esse espaço racional e orgânico corresponde um outro "invisível", "subjetivo", "emocional", "molecular", ligada à memória e ao desejo, que Olivieri (2011), inspirada nas formulações de Deleuze, denomina espaço "inorgânico" ou "cristalino". Para a autora, a cidade:

$110 \frac{\text { Comunicação \& Inovação, PPGCOM/USCS }}{\text { v. 17, n. } 34(105-119) \text { maio-ago. } 2016}$ 
como todo "misto" tem uma faceta visível, transparente, atual e exterior, que desempenha funções objetivas, organiza-se por agenciamentos molares e se desenvolve na extensão, em movimentos no espaço; como também uma faceta invisível, opaca, virtual e interior, que cumpre uma função subjetiva ou afetiva, configura-se por agenciamentos moleculares e se desenvolve na duração, em movimentos no tempo [...] essas duas faces urbanas estabelecem uma relação que Deleuze definiu como "pressuposição recíproca" ou "reversibilidade": os elementos que as compõem, em vez de se oporem ou negarem, se articulam e se imbricam, formando circuitos de trocas mútuas. (Ibid., p. 23).

Ao serem ativados, esses circuitos de trocas mútuas constituem uma modalidade particular de espaço (como também de relação com ele) que resulta nos espaços "inorgânicos" ou "cristalinos". A importância da abordagem cristalina da cidade é que ela considera os espaços de alteridade, justamente por levar em conta os diferentes graus de intervenções dos habitantes da cidade 3 . Com efeito, "nenhuma cidade, por mais planejada e controlada que seja, consegue evitar a eclosão de focos de desordem, de distúrbios nos seus programas e estruturas, de transformações por vias não previstas" (Ibid., p. 24). Como esclarece Olivieri, as liminaridades ou os intercâmbios entre essas duas facetas da cidade têm como uma das referências primordiais o tempo. Com base na atenção ao tempo, podem-se compreender melhor os modos de experiência engendrados na cidade. No espaço orgânico, o tempo é racional, idealizado, próprio dos calendários, isto é, um tempo contínuo e linear, da "repetição" e do "mesmo". Contrariamente, o tempo cristalino é fragmentário e descontínuo, aberto à experiência vivida, às transformações e aos devires; há aqui uma distensão temporal perfeitamente apta a incorporar a lentidão, os ritmos menos exatos próprios à vida ordinária e ao cotidiano. "Se o outro espaço era abstrato e idealizado, aqui temos o espaço frágil, estilhaçado e embaçado da vida, da experiência vivida" (Ibid., p. 25). Essas noções distintas de tempo interferem diretamente na experiência dos habitantes da cidade, ou, melhor dizendo, são as próprias experiências que conformam a relação temporal: a cidade da experiência cristalina é colocada em prática pelos habitantes ordinários ou aqueles que inventam espaços de exceção em relação às regras da cidade formal - no dizer de Santos (2008), os "homens lentos", que vivem o tempo do aproximativo e não da exatidão, o tempo da lentidão e não da vertigem.

3 A autora ressalta a existência de dois modos de abordagem da cidade pelo urbanismo, que estão ligados aos modos de identificação e produção do espaço orgânico e do espaço inorgânico ou cristalino. $\mathrm{O}$ modo orgânico "é próprio da vertente dominante e hegemônica do urbanismo desde seus primórdios por isso, normalmente é confundido com o próprio campo; o segundo modo, cristalino, caracteriza uma vertente minoritária, marginal, dissidente" (OLIVIERI, 2011, p. 31). A abordagem orgânica se liga à tradição moderna do urbanismo e nega o circuito de trocas entre o caráter objetivo e subjetivo da cidade, mantendo uma visão panóptica e panorâmica do espaço urbano; a abordagem cristalina desvia-se da tradição para considerar a interação e a relação das faces objetiva e subjetiva da cidade. 
No caso do filme de Gabriel Mascaro, em que o cotidiano dos personagens-atores é tomado como ponto de vista, a forma fílmica adota um tom menor para focalizar a vida miúda, mostrando-se em relação de contiguidade com o espaço-tempo vivido pelos sujeitos filmados; esse contágio entre linguagem e experiência apresenta consequências sobre a escritura do filme, que se torna discreta, duradoura e nada espetacular. A temporalidade do filme, em vizinhança com o mundo vivido, revela-se fragmentária, em episódios que inscrevem práticas sociais e fazeres dos sujeitos filmados, como discutiremos a seguir.

\section{A construção do tempo e do espaço na encenação}

Há na proposição estética de Avenida Brasília Formosa um trabalho de imanência que resulta em imagens que se fazem coladas ao mundo, deixando-se impregnar pelos tempos fracos da vida ordinária, por seus ritmos. A temporalidade do filme busca traduzir os tempos anódinos da rotina e a duração das ações corriqueiras, o que torna muitas imagens lacônicas e silenciosas. A temporalidade cifrada pela escritura é tributária de escolhas estéticas bem definidas, como um trabalho de câmera que prima pela duração das imagens, a utilização de planos bastante distendidos, associados por uma montagem discreta.

Não por acaso, o filme é repleto de passagens que registram ações portadoras de uma lentidão que contagia a duração da tomada. Vemos algo assim quando acompanhamos Débora descascando um abacaxi na cozinha de sua casa e a ação transcorre quase em tempo real. Ficamos alguns instantes com a imagem e temos condições de observar o ambiente doméstico, a disposição dos móveis, dos utensílios. A cena não apresenta nada de extraordinário; o que mais se evidencia nesse trecho são os tempos fracos e não marcados do cotidiano, que emergem no espaço embasado da vida comum.

Desde suas primeiras sequências, Avenida Brasília Formosa nos coloca em contato com os personagens-atores desempenhando ações rotineiras em cenas que não parecem perseguir uma finalidade em si, no sentido da criação de uma narrativa com início, meio e fim, que guarda traços de teleologia. O filme também não apresenta preocupações com a criação de um clímax ou grande final. Prevalecem as ações rotineiras, que são apanhadas numa narrativa desamarrada. O que ganha força nas imagens são os segmentos descontínuos do cotidiano, que nos causam a impressão de presenciarmos cerca de três dias na vida dos sujeitos da cena.

Assim, o espaço da cidade vai sendo inscrito num recorte de tempo bem definido: o presente, lócus privilegiado da experiência. Não por acaso, a dimensão temporal apresentada no filme guarda relação estreita com a espacialidade criada, pois ambas as categorias dimensionam os afetos contidos na vida mais prosaica. Na inscrição espacial, nota-se 
o uso recorrente dos planos médios, que primam por situar os corpos em relação aos ambientes. Essa escolha cria uma cena fortemente marcada pelo vínculo entre os espaços e as pessoas que os habitam. Estamos, pois, diante de espaços encarnados, portadores de indícios da experiência social. É assim que vemos Pirambu, o pescador, no interior de sua embarcação, preparando macarrão com salsicha na velha panela de alumínio, ao som da música popular que toca no rádio e insinua algo do imaginário romântico que ressoa as vivências ali contidas, tornando o espaço filmado povoado das marcas humanas. Numa das passagens, vemos Fábio indo à casa de Fabíola, sua vizinha costureira, para encomendar as roupas da apresentação coreográfica que fará na igreja e negociando o preço e a data de entrega num tom tão amigável que não resta dúvida sobre a sociabilidade que ali se instala, aquela de vizinhança, que pode descartar os acordos formais. Já Pirambu, na volta do trabalho, passa na venda, compra pão, cigarro e uma Frevo, cerveja local. Numa das noites de pesca, Pirambu e os companheiros adentram o mar no pequeno barco. $\mathrm{O}$ rádio toca uma canção e Pirambu canta junto: "moça bonita eu estou na solidão, moça bonita cuida do meu coração". Depois disso, eles fazem pilhéria do companheiro que passou algumas noites na cadeia: "o delegado falou pra ele que ali não era hotel”, conta divertido Pirambu. Todos riem e comentam que o pescador se livrou por pouco da Lei Maria da Penha.

Essas situações que marcam encontros e diálogos revelam como os personagens interagem e fazem laços sociais, atestando a presença de uma vida comum. As conversações traduzem o sotaque dos habitantes de Brasília Formosa, mas, sobretudo, remetem ao saber ordinário, ao universo simbólico por eles compartilhado. Nas falas transparecem os modos de expressão, a oralidade. Contudo, é interessante notar que essas cenas não se fazem emblemáticas no sentido de não remeterem a uma identidade social ou de classe, de maneira determinante ${ }^{4}$. Quando a câmera passeia pelas ruas do bairro, torna-se reconhecível a heterogeneidade dos modos de vida dos habitantes de Brasília Formosa: há roupas dependuradas nos varais ou nas janelas das casas, populares em suas atividades diárias, alguns deles tomando ar na porta das moradias, pessoas trabalhando, crianças brincando, garotos jogando pelada à beira-mar, gente transitando nas vielas, os corpos suados no forró, os ônibus lotados trafegando na avenida que leva ao mar. Esses instantes capturados como que ao acaso, no meio do dia ou da noite, sempre embalados pela música popular que serve de trilha sonora ao filme, são como que pedacinhos do sensível; eles abrigam

4 Lembremos que o cinema nacional, ao longo de sua história, acionou diversas vezes procedimentos interpretativos totalizantes na figuração dos segmentos populares, criando identidades emblemáticas ou representativas que conectavam os personagens com a história, como se observa no caso dos personagens migrantes, camponeses, pescadores, moradores de favela e operários. Tais classificações generalizantes, se dizem muito sobre as identidades em questão, dificultam a compreensão das singularidades e das trajetórias individuais dos personagens. 
situações tão diversas que não permitem ser facilmente codificadas ou identificadas, até porque as pessoas comuns se fazem presentes na cena sob as mais diversas expressões, $o$ que dificulta a tentativa de essencialização.

$\mathrm{Na}$ cidade criada pelo filme, prevalece a fórmula ensinada por Comolli (2008), que contraria aquela do cinema clássico: em vez de filmar corpos nos cenários, talvez caiba ao cinema exibir os cenários que seriam levados nos corpos. Segundo o autor, "o cinema nos confronta com aquilo que, de cada cidade filmada, justamente não se reduz à sua dimensão visível" (Ibid., p. 180). Ao inscrever o invisível da cidade, afirma o autor, o cinema recompõe, como experiência, os espaços e as vidas. O que ele filma:

são as vidas que passaram por aí, os corpos, as palavras, as narrativas, todo o emaranhado de encontros tão intensamente vividos quanto rapidamente perdidos. Filmada, a cidade se torna texto, hipertexto, e mesmo, simultaneamente, coletânea de todas as histórias possíveis nas cidades e léxico de todas as palavras trocadas. (loc. cit.).

Os espaços matizados no filme são também povoados de sonoridades. Na sequência de abertura de Avenida Brasília Formosa, vemos casas simples de tijolos, com sua arquitetura irregular. O plano é bastante duradouro. Contudo, esse não é um plano realizado somente para mostrar o espaço físico; sua imagem se faz potente quando uma profusão de ruídos vem compor a cena, denunciando a presença de um enorme fora de campo. Há um mundo lá fora que se expande pelas bordas do quadro, no qual uma estação de rádio toca um tecnobrega, ondas do mar se quebram, crianças riem, mulheres conversam, carros trafegam e outra música parece competir com a primeira. Esses sons se repetem durante toda a narrativa, criando espacialidades carregadas de afeto por serem recobertas da fala e do sotaque locais. A polifonia presente na cena se torna responsável pela criação de espacialidades sonoras que ampliam a cidade, revelando a heterogeneidade da vida existente no bairro. No mesmo sentido atua a trilha sonora, que também cria espacialidades, propondo vizinhanças ao relacionar ações que não têm ligação entre si (quando o som serve de passagem aos cortes secos entre os planos que levam de um personagem a outro), ou entre os espaços (quando torna contíguas as cenas da casa e da rua) e mesmo ligando trajetórias distintas (quando, por exemplo, as longas caminhadas de Fábio são substituídas pelas de Débora e, justamente, a trilha sonora facilita as passagens, tornando contínuos e comuns espaços originariamente diferentes).

Em relação à composição dos espaços, podemos falar, ainda, sobre uma geografia criadora da cidade que se efetiva com as perambulações dos personagens. Aqui são 
as caminhadas que desenham o espaço que o espectador experimentará. Se uma cidade é criada no filme por meio dessas andanças, não se pode esquecer que os trajetos feitos a pé, como deriva, falam também de pertencimento, de apropriação, ou seja, dos usos e das invenções dos usuários. Certeau (2011) chega a comparar o ato de caminhar no sistema urbano ao ato de enunciação na língua. O caminhar, diz Certeau, abriga uma função enunciativa por constituir uma realização espacial do lugar, uma forma de apropriação do sistema topográfico pelo pedestre, assim como o locutor se apropria da língua.

$\mathrm{O}$ espaço criado no filme, que se configura também a partir das andanças dos personagens, ganha constituição definitiva com o trabalho da montagem cinematográfica. Cezar Migliorin já havia proposto que a montagem em Avenida Brasília Formosa cria vinculações entre os espaços e os personagens, colocando em jogo blocos de afetos na inscrição da cidade: "a montagem conecta as vidas e espaços e deixa, entre eles, uma linha que os vincula, um pertencimento a um espaço urbano" (MIGLIORIN, 2011, p. 165).

Assim, por meio de conexões, a mise-en-scène de Avenida Brasília Formosa invariavelmente reúne personagens e espaço social. A partir da própria escritura (montagem), o filme propõe ligações. Mas também no interior da diegese há vinculações (vemos Fábio encontrar Débora e Cauan) e quase sempre os sujeitos da cena interagem com outras pessoas, estabelecendo alianças e intensificando o sentido de espaço comum que a narrativa sugere. Se existem microuniversos, há entre eles vielas, corredores, a praia que todos frequentam no fim de semana. Os espaços ganham vida e não se colocam como puramente objetivos. A montagem do filme é um dos recursos expressivos definitivos a propor o alinhamento entre a criação do espaço social e do espaço fílmico.

Contudo, as diferenças irredutíveis entre a cidade planejada e os espaços dos sujeitos ordinários não desaparecem por completo. No filme, os mundos em confronto encontram seu maior emblema na imagem das "torres gêmeas", que mudaram definitivamente a paisagem de Recife. A mise-en-scène deixa que as enormes edificações façam parte do registro como forma de marcar os contrastes, a existência dos problemas. Na praia, a câmera abandona deliberadamente os momentos de lazer de Débora e Cauan para realizar um longo travelling pelos arranha-céus erguidos na orla. De fato, em grande número de tomadas externas, quando os personagens caminham, passeiam ou vão para o trabalho, as torres se fazem notar dentro do quadro, o que denuncia o trabalho da planificação ${ }^{5}$. A presença dessa demarcação simbólica que as torres codificam demonstra como as relações em Avenida Brasília Formosa são complexas porque o cotidiano é

5 O papel da planificação é definir um lugar para a colocação da câmera, bem como os pontos de vista que ela assumirá. Isso significa que no momento da tomada já se está operando alguma forma de montagem, que modula e modela os tempos, modificando infinitamente os pontos de vista da cena, se preciso for. 
cerrado, atravessado por muitas forças, não se oferecendo simplesmente como lugar de pura autonomia para os sujeitos. Há uma face dura que se expõe, num cotidiano árduo, que não permite a reconciliação completa dentro do espaço urbano. Por meio de poderes, mundos em disputa, se faz sentir as forças do capital. Se Pirambu percorre longa distância de bicicleta entre sua nova casa e o mar, é porque os moradores da favela de palafitas à beira-mar foram removidos para um conjunto habitacional do outro lado da cidade. É nesse conjunto de prédios que a sogra de Pirambu se queixa, dizendo ao pescador que depois da remoção nunca mais dormiu direito devido ao intenso barulho que existe no Habitacional Cordeiro; no mesmo diálogo, confessa estar irritada, pois alguém teria lhe dito que ela agora mora num chiqueiro.

Não é mero acaso que o filme analisado se concentra no espaço urbano. É que a cidade condensa hoje os maiores dilemas sociais e políticos, as maiores desigualdades; é na cidade que se situam as mais pesadas disputas em torno dos desejos. Como notam Guattari e Rolnik (1986), a disputa em torno dos desejos encontra-se no cerne da micropolítica atual porque o capitalismo contemporâneo visa minar todas as situações que contribuem para a emergência das singularidades, essas que se enraízam na experiência, que se abrem à invenção, às novas formas de vida, a todos os possíveis. Ao capitalismo interessa, pois, a homogeneização das subjetividades.

\section{"Espaços outros": a invenção de mundos possíveis}

Ao analisar Avenida Brasília Formosa, buscando compreender as formas que construíram suas espacialidades e temporalidades, tivemos como referência a contribuição de Comolli (2008). O autor propõe que a representação é um campo de forças no qual a alteridade não apenas figura, mas é constitutiva das relações. Isso pressupõe pensar nas cenas que envolvem os que filmam, os que são filmados e o espectador. Para Comolli (2008), essa tríade que se configura no plano das representações, além de colocar em confronto os mundos dos sujeitos que filmam e dos que são filmados, prevê também o lugar do espectador sujeito inventado pelo cinema, atravessado pela experiência ofertada pelo filme:

Assim como a projeção de um filme não se desenrola apenas na tela da sala, mas também na tela mental do espectador, o espectador que o cinema supõe não está (apenas) diante do filme, mas no filme, capturado e desdobrado na duração do filme. (Ibid., p. 97).

Esses entendimentos contribuem para situarmos o modo como a representação está estreitamente ligada à escritura fílmica, aos modos de abordagem daquilo que é filmado 
e, evidentemente, às relações de poder que entram em jogo antes mesmo do momento da tomada. O cerne da questão é como o cinema coloca em jogo as várias cenas que compõem a representação, os mundos em confronto, e como maneja recursos expressivos para inscrever o universo do Outro. É nesse sentido que a representação exerce sempre uma função mediadora, que não se restringe ao mero registro. Ela é fruto de escolhas de abordagem e de recursos expressivos. Isso significa compreender o filme como coisa construída, que elege elementos do mundo para redimensioná-los, instaurando novos regimes de sensibilidade, novas formas de percepção sobre o mundo real e histórico, recriado na duração das imagens.

Para inscrever uma cidade em Avenida Brasília Formosa, foi preciso eleger procedimentos formais e percorrer o espaço menos iluminado da vida miúda. Esse percurso traduziu-se na criação de um espaço sensível que se confunde com os afetos dos sujeitos da cena. Ao fazê-lo, o filme evitou a estereotipia e as maneiras já bastante codificadas de mostrar os espaços do Outro (os subúrbios, a favela e os lugares onde os sujeitos ordinários habitam cotidianamente). Se a escolha foi por mostrar a vida pobre nas grandes cidades, onde as favelas são territórios envolvidos nas maiores disputas sociais e políticas, a narrativa não o fez sob o signo exclusivo da violência ou da precariedade material, mas privilegiou uma visada produtiva do universo encenado.

Assim, o filme articulou uma voz resistente aos poderes midiáticos e do capital ao colocar-se criticamente frente às relações de poder existentes no mundo histórico. Seu gesto político evidenciou-se na escolha por procedimentos e recursos expressivos capazes de criar outras formas sensíveis, outras formas que convocam o espectador a experimentar os lugares desprivilegiados da cidade (lugares portadores de índices de alteridade), mas agora constituídos na organização espaço-temporal do próprio filme. Rancière (2005) afirma que a arte (assim como a política) é uma das maneiras de partilhar o sensível e que a obra de arte é potente para reconfigurar o território das visibilidades e sensibilidades. Um filme pode contrapor a cena por ele engendrada àquelas do mundo social, convocando os espectadores a partilhar outras formas sensíveis a partir da articulação que propõe entre espaço, duração, corpo e voz filmados. No entendimento de Rancière, a política ao alcance do cinema está em propor novas formas estéticas e colocá-las em comum, propondo uma nova partilha. Na trilha de Rancière, Migliorin (2010, p. 43) afirma:

as operações dos poderes são essencialmente estéticas. Os poderes se efetivam modulando formas de ocupação do espaço e do tempo, o que configura formas específicas de sentir e atuar na comunidade, de tracejar o que é comum e o que tem pertencimento exclusivo. Assim, para refletir sobre as relações dos poderes com os indivíduos no contemporâneo, não podemos nos distanciar de seus modos de ação, que atuam estimulando, modulando e gerindo essas estéticas. 
Diante das relações sempre tensionadas entre os poderes que vigoram nas cidades e a vida das pessoas comuns, o filme preferiu investigar as formas de sociabilidade cotidianas, revelando seus movimentos moleculares e os modos de aderência dos sujeitos filmados ao mundo vivido. Ao relatar o espaço pelo viés da experiência cotidiana, a encenação revelou a coexistência de mundos - escolha fundamental para que o espaço inscrito não se mostrasse isolado ou mantido à parte (como uma zona de pureza). Trata-se, antes, de um espaço polissêmico que pode assim ser definido em função das multiplicidades que o conformam. O que definiu o espaço foram os entrecruzamentos e as sobreposições de forças advindas do mundo social capazes de desestabilizar as posições demasiado fixas.

No filme, o espaço pode ser compreendido como uma passagem, uma reentrância, na qual os elementos bem marcados do mundo social convivem com outros não tão marcados. Esse pequeno "território" criado na encenação se assemelha a uma franja existente dentro de um espaço maior. O posicionamento desse espaço é definido pela relação dialética entre o local e o global, entre o longe e o perto, entre os poderes e as resistências. Retomando o pensamento de Foucault (2006), podemos dizer que os espaços no mundo hoje são exatamente esses que sofrem o atravessamento fatal do tempo, conforme sugere o filósofo: "A época atual seria talvez de preferência a época do espaço. Estamos na época do simultâneo, estamos na época da justaposição, do próximo e do longínquo, do lado a lado, do disperso" (Ibid., p. 411). No mundo atual, afirma Foucault, o espaço se oferece sob a forma de "relações de posicionamentos", isto é, pelas relações de vizinhança entre variados pontos e elementos. Por isso, situa o autor, não vivemos em espaços "homogêneos" ou "vazios", mas em espaços recobertos por movimentos, qualidades, cruzamentos. Reconhecer um espaço significa identificar o conjunto de relações que permitem defini-lo. Segundo o filósofo, filiam-se a esses tipos de espaços as heterotopias, que se caracterizam por serem:

lugares reais, lugares efetivos, lugares que são delineados na própria instituição da sociedade, e que são espécies de contraposicionamentos, espécies de utopias efetivamente realizadas nas quais os posicionamentos reais, todos os outros posicionamentos reais que se podem encontrar no interior da cultura, estão ao mesmo tempo representados, contestados ou invertidos, espécies de lugares que estão fora de todos os lugares, embora eles sejam efetivamente localizáveis (Ibid., p. 415).

As heterotopias são, pois, "lugares outros", "espaços diferentes", que realizam uma oposição mítica e real em relação ao espaço em que vivemos. Notamos, assim, como as heterotopias citadas por Foucault se prestam à projeção do espaço existente na vida social, aquele ligado às práticas e fazeres, aquele espaço efetivamente vivido, que existe dentro de um espaço maior, sem, no entanto, nele se dissolver. 
No caso de Avenida Brasília Formosa, pensamos que o cotidiano encenado vem compor algo à maneira de uma heterotopia microscópica, em escala mínima, que permite que algo do Outro ali se afirme. Se a narrativa nos colocou diante daquilo que torna os sujeitos singulares, foi por mostrar os modos múltiplos como eles vivem, as maneiras nada convencionais como habitam, percorrem, amam e se reinventam. As escolhas da mise-en-scène conferiram aos sujeitos da cena "a chance de exibir o aparecer simultâneo de suas múltiplas faces, a impropriedade de seu rosto, a comunicabilidade pura de sua fala, irredutível a uma proposição ou conteúdo determinado" (GUIMARÃES, 2006, p. 41). As escolhas estéticas foram definitivas para inscrever o rumorejar da vida do Outro, presente muito mais em afetos e crenças, que sob os traços rígidos da identidade. Ao se abrir à vida cotidiana e aos desvios inventivos dos sujeitos da cena, o filme permitiu que o universo ficcionado multiplicasse as formas de estar no mundo.

\section{Referências}

AUMONT, J.; MARIE, M. Dicionário teórico e crítico de cinema. Campinas, São Paulo: Papirus, 2003.

CERTEAU, M. A invenção do cotidiano: artes do fazer. Petrópolis: Vozes, 2011.

COMOLLI, J.-L. Ver e poder. A inocência perdida: cinema, televisão, ficção, documentário. Belo Horizonte: UFMG, 2008.

FOUCAULT, M. Outros espaços. In: BARROS DA MOTTA, M. (Org.). Estética: literatura e pintura, música e cinema. Rio de Janeiro: Forense Universitária, 2006. p 411-422.

GUATTARI, F.; ROLNIK, S. Micropolítica: cartografias do desejo. Petrópolis: Vozes, 1986.

GUIMARÃES, C. A singularidade como figura lógica e estética no documentário. Revista ALCEU, Rio de Janeiro, v. 7, n. 13, p. 38-48, 2006.

LEFEBVRE, H. O direito à cidade. São Paulo: Centauro, 2001.

MIGLIORIN, C. 5 x favela - agora por nós mesmos e Avenida Brasília Formosa: das possibilidades de uma imagem crítica. Devires - Cinema e Humanidades, Belo Horizonte, v. 7, n. 2, p. 41-55, 2010. . Escritas da cidade em Avenida Brasília Formosa e O céu sobre os ombros. Revista do Programa de PósGraduação da Escola de Comunicação da UFRJ (Eco-Pós), Rio de Janeiro, v. 14, n. 1, p. 162-176, 2011.

OLIVIERI, S. Quando o cinema vira urbanismo: o documentário como ferramenta de abordagem da cidade. Salvador; Florianópolis: EDUFBA, PPGAU; ANPUR, 2011.

RANCIÈRE, J. A partilha do sensível: estética e política. São Paulo: Editora 34, 2005.

SANTOS, M. Por uma outra globalização: do pensamento único à consciência universal. Rio de Janeiro: Record, 2008.

SOJA, E. W. Geografias pós-modernas: a reafirmação do espaço na teoria social. Rio de Janeiro: Zahar, 1993. 